\title{
IDENTIDADE PROFISSIONAL E FORMAÇÃO DE PROFESSORES DE PORTUGUÊS COMO LÍNGUA ADICIONAL Na COLômbia
}

\author{
IDENTIDAD PROFESIONAL Y FORMACIÓN DE DOCENTES DE PORTUGUÉS \\ COMO LENGUA ADICIONAL EN COLOMBia \\ Professional Identity and Education of Teachers of Portuguese \\ as an Additional Language in Colombia
}

\author{
Luciana Andrade-Stanzani \\ Doutora em Educação, Universidad \\ de los Andes, Colômbia. \\ Coordenadora pedagógica da área \\ de Português, Departamento de \\ Lenguas y Cultura, Universidad de \\ los Andes, Colômbia. \\ l.andrade1067@uniandes.edu.co \\ https://orcid. \\ org/0000-0002-6029-6304
}

\begin{abstract}
RESUMO
Por diferentes razões culturais, sociais, e políticas, a maioria dos professores de português como língua adicional (PLA) na Colômbia são falantes nativos sem formação específica na área de línguas. Nesse contexto, esta pesquisa se pergunta pelas trajetórias profissionais desses professores falantes nativos. Com o objetivo de (re)conhecer seus processos de formação, entrevistamos a vinte e cinco professores de PLA em seis cidades colombianas. Com o uso da metodologia qualitativa de teoria fundamentada, encontramos a categoria de análise: "debute profissional e formativo" que explica como esse grupo se identifica com a docência. Concluímos que os professores se identificam com as aulas de PLA na Colômbia por se reencontrarem com a língua e a cultura brasileira. Mesmo assim, os entrevistados afirmam sentir necessidades específicas de formação docente. Dessa forma, constatamos a extrema necessidade de cursos de graduação e/ou licenciatura orientados para a formação desse profissional na Colômbia.
\end{abstract}

Palavras-chave: professores de português; falante nativo; identidade do professor; Português como Língua Adicional; PLA.

\section{RESUMEN}

Por diferentes razones culturales, sociales y políticas, la mayoría de los profesores de portugués como lengua adicional (PLA) en Colombia son hablantes nativos que carecen de formación específica en el campo de las lenguas. En ese contexto, esta investigación se pregunta por las trayectorias profesionales de esos profesores hablantes nativos. Con el objetivo de (re)conocer sus procesos de formación, entrevistamos a veintincinco profesores de PLA en seis ciudades colombianas. Usando la metodología cualitativa de la teoría fundamentada encontramos la categoría de análisis: "debut profesional y formativo" que explica cómo ese grupo se identifica con la docencia. Concluimos que los profesores se identifican con la enseñanza de PLA en Colombia como un espacio donde pueden reencontrarse con la lengua y la cultura brasileñas. A pesar de eso, los entrevistados afirman sentir necesidades específicas de formación docente. Así, constatamos la urgente

Recebido: 2020-05-31/ Aceito: 2020-11-10 / Publicado: 2021-05-05

https://doi.org/10.17533/udea.ikala.v26n2a02 
necesidad de una oferta de cursos de pregrado o licenciatura orientados a la formación de esos profesionales en Colombia.

Palabras clave: profesores de portugués; hablante nativo; identidad del docente; portugués como lengua adicional; PLA.

\section{Abstract}

For various cultural, social and political reasons, most of Portuguese-as-an-additional-language (PLA) teachers in Colombia are Portuguese "native speakers". However, these teachers lack specific training in the field of language teaching. In that context, this research asks about the professional trajectories of these native speaker teachers. In order to inquire about their training processes, we interviewed twenty-five PLA teachers in six Colombian cities. Using a qualitative approach and a grounded theory methodology, we found "professional and formative debut" as a category of analysis that explains this group's identification with language teaching. We concluded that PLA teachers in Colombia identify with their work as a way to reconnect themselves with Brazilian language and culture. Despite this, the interviewees state they perceive specific needs regarding teacher training. Thus we can confirm the urgent for diploma or undergraduate courses aimed at training these professionals in Colombia.

Keywords: Portuguese teachers; native speaker; teacher's identity; Portuguese as an additional language; PLA. 


\section{Introdução}

Esse artigo deriva de uma pesquisa doutoral sobre formação de professores de Português como Língua Adicional (PLA) na Colômbia. Decidimos nos valer do termo PLA devido ao fato de que os estudantes colombianos, geralmente, aprendem português como terceira ou quarta língua. Nesse caso, língua adicional se aplica a todas as línguas, exceto, a primeira língua aprendida (Elliot et al., 2001, p. 6). Além disso, decidimos nos valer do termo PLA porque a língua portuguesa é falada por muitos colombianos na fronteira com o Brasil e por isso não a consideramos estrangeira no contexto desse país. Assim, consideramos que o uso do termo PLA reconhece a contribuição da língua portuguesa na construção de um repertório linguístico mais amplo (Schlatter e Garcez, 2009).

Nesse contexto, a maioria dos professores de PLA são falantes nativos, isso ocorre por diferentes razões: a valorização da figura do professor nativo nesse campo da educação, a falta de uma política linguística articulada tanto pelo Brasil como pela Colômbia na construção de projetos educacionais que promovam a integração latino-americana, a carência de cursos de formação de professores de PLA na Colômbia ${ }^{1}$, entre outras.

Independentemente das razões mencionadas anteriormente, é crescente o interesse dos colombianos por aprender português. Dessa forma, a falta de uma formação específica na área de línguas não foi impedimento para que esses profissionais falantes nativos desenvolvessem uma carreira como professores de PLA na Colômbia. Nesse contexto, é válido perguntarmos sobre a trajetória desses profissionais no ensino da língua portuguesa. Assim, esta pesquisa tem como objetivo geral re(conhecer) os processos de formação profissional desse grupo. De maneira específica buscamos compreender como os professores

$1 \mathrm{Na}$ Colômbia, encontramos apenas uma licenciatura em língua portuguesa a da Fundación Universitaria Juan $N$ Corpas. A instituição oferece esse curso desde 2018 e tem como objetivo formar professores para o ensino de línguas estrangeiras inglês (C1) com ênfase em português (B2). entram em contato e se identificam com a docência, como se vinculam aos contextos de trabalho na Colômbia, como se identificam profissionalmente e quais são suas necessidades de formação.

Com a intenção de responder a todas essas perguntas, realizamos um estudo qualitativo baseado na teoria fundamentada (Charmaz, 2009), onde entrevistamos vinte e cinco professores de PLA em seis cidades colombianas. A partir da codificação linha a linha e da análise do corpus das entrevistas, identificamos a categoria "debute profissional e formativo" que explica os processos de construção profissional desse grupo.

Com o objetivo de demonstrar o estudo realizado, esse artigo está dividido da seguinte forma: em primeiro lugar apresentamos alguns antecedentes que nos ajudarão a entender o problema de formação de professores de PLA no contexto colombiano. Depois, discutimos algumas perspectivas teóricas e práticas sobre a formação de professores de PLA e apresentamos um estado da arte com algumas pesquisas sobre o tema. Em seguida, argumentamos sobre a metodologia de pesquisa empregada e identificamos os participantes desse estudo. Por último, apresentamos os resultados seguidos de uma discussão e das conclusões dessa investigação.

\section{Antecedentes sobre o ensino e a formação de professores de PLA na Colômbia}

$\mathrm{Na}$ Colômbia, o ensino de PLA é oferecido em escolas, universidades e instituições não formais. Alguns colégios em Bogotá como o Nueva Granada oferecem cursos de português como matéria optativa (Patiño, 2005). As principais universidades do país como Universidaddelos Andes, Universidaddel Norte, Universidad Nacional de Colombia, Universidad de Antioquia, entre outras, também oferecem cursos livres de português. Além desses contextos de ensino, é possível encontrar outras instituições não formais que oferecem cursos de português no país, entre essas destacamos o Instituto de Cultura Brasil Colômbia (IBRACO) que recebe cerca de 600 candidatos para 
o exame Celpe-Bras nas cidades de Bogotá, Cali, Medellin, Letícia e Bucaramanga².

Segundo dados da Embaixada do Brasil em Bogotá ${ }^{\text {, }}$ a Colômbia é o maior posto aplicador do exame Celpe-Bras no mundo, com 958 candidatos em 2017. Esses números são reflexo da aspiração dos colombianos em estudar no Brasil: "a Colômbia tem sido um país repetidamente beneficiado pelo programa de bolsas nos últimos anos, com um total de 644 bolsas entre os anos de 2005 e 2016, representando 28\% do total de bolsas oferecidas pelo Brasil" (Andrade-Stanzani, 2019, p. 181). Esses dados demonstram o crescente interesse dos colombianos em aprender e certificar a língua portuguesa.

Apesar da ampla oferta de cursos de português na Colômbia e dos seus números expressivos com relação ao exame Celpe-Bras, é difícil encontrar cursos de graduação que possam formar professores para atuar nessa área. Na maioria dos contextos universitários, a oferta de cursos de língua portuguesa é de caráter optativo. Por experiência da autora, é difícil encontrar programas acadêmicos dedicados à promoção e pesquisa da língua portuguesa. Os cursos de português ofertados nas universidades colombianas são, na maioria das vezes, cursos livres desvinculados de programas de licenciatura. Inclusive, a maioria dos cursos de licenciatura de língua estrangeira no país são de espanhol, inglês, francês e alemão.

Segundo Patiño (2005), a criação de uma linha profissional para a formação de professores de português é vital. Porém, identificamos que o governo colombiano tem políticas linguísticas que se esforçam no investimento e fortalecimento do ensino de inglês em detrimento de outras línguas, como é o caso do Programa Nacional de Bilinguismo (Cárdenas, 2010).

2 http://cultura.gov.br/instituto-de-cultura-brasil-colombia-ganha-nova-sede/. Acesso 25 de outubro de 2020.

3 http://bogota.itamaraty.gov.br/es-es/certificado_de_ proficiencia_en_lengua_portuguesa-celpe-bras.xml. Acesso 25 de outubro de 2020.
No Brasil, a oferta de cursos de graduação na área de PLA também é escassa, são poucas as universidades que oferecem o programa em Letras. Segundo Scaramucci (2012) existiam, nessa época, apenas dois cursos específicos para a formação de professores de PLA no país. Atualmente, identificamos quatro instituições que oferecem essa formação: a Universidade de Brasília (UNB), a Universidade Estadual de Campinas (Unicamp), a Universidade Federal da Bahia (UFBA) e a Universidade Federal da Integração Latino-Americana (Unila). Além dessas iniciativas, encontramos alguns programas de extensão assim como algumas disciplinas oferecidas em determinadas graduações em Letras para a formação desse profissional.

Esses antecedentes mostram que apesar de que a Colômbia tenha números expressivos de estudantes de PLA, não evidenciamos políticas e/ou cursos de formação profissional a contento para os professores dessa área. $\mathrm{Na}$ próxima sessão de marco teórico, discutimos algumas perspectivas sobre a formação de professores de PLA.

\section{Marco teórico}

Grannier (2001) afirma que a formação do professor de Português como Segunda Língua (PSL) deveria apontar ao perfil de um especialista em língua que reconhece os processos de aquisição, bem como as metodologias e abordagens que envolvem os processos de ensino e aprendizagem dessa. Identificamos em Almeida Filho (1993) a materialização da formação do professor de PSL proposta por Grannier (2001) na realização das seguintes ações:

1. Planejar as aulas.

2. Preparar e/ou selecionar os materiais de ensino.

3. Definir os construtos teóricos que orientam suas práticas (método/abordagem).

4. Avaliar e valorar os processos e resultados do ensino.

É necessário reconhecer que ditas ações devem ser consideradas nos cursos de formação de professores 
de PLA com uma série de princípios, pressupostos e crenças que constituem e situam os professores em sua própria maneira de ensinar. Nesse sentido, se argumenta que quando os professores se (re)conhecem nas dimensões que constituem suas práticas, podem refletir sobre o que realizam e isso proporciona uma análise sobre como ensinar - ganhando consciência de si mesmos em seu papel como profissionais docentes.

Ainda para Almeida Filho (1993), o paradigma do professor é aquele que desenvolve a capacidade de pensar sistematicamente sobre o exercício do ensino, a fim de, eventualmente, melhorá-lo. Encontramos nessa proposta que o professor deve ser um sujeito consciente de sua prática e autônomo nos processos de ensino e aprendizagem de uma língua, de acordo com o contexto específico em que atua. As ideias de Almeida Filho (1993) dialogam diretamente com as propostas de profissional reflexivo (Schön, 1991) e a figura do professor pesquisador de sua prática (Elliott, 1991; Stenhouse, 1996), porém decidimos delimitar a construção desse marco teórico com a discussão de propostas de formação de professores especificamente de PLA.

Gimenez (2005) argumenta que a formação desse profissional enfrenta pelo menos sete desafios:

1. A definição de quais são os conhecimentos básicos para a formação profissional.

2. O papel da pesquisa na formação de professores.

3. O encontro de uma abordagem articulada entre teoria e prática.

4. Um estudo qualitativo e quantitativo sobre o impacto e a sustentabilidade das propostas de pesquisa na área.

5. A implementação de resultados de pesquisa como diretrizes para políticas públicas na formação de professores.

6. A construção e compreensão da identidade profissional dos formadores.

7. Romper com a clássica separação entre formação inicial e contínua de professores, criando espaços para discussão e análise crítica da prática docente.
Garcez e Schlatter (2017) propõem a figura dos professores autores no contexto da formação docente. $\mathrm{O}$ conceito de autor "implica construir a própria singularidade nas atividades em que alguém participa e assumir a responsabilidade pela singularidade produzida” (Garcez e Schlatter, 2017, p. 18). Nesse caso, a autoria tem três dimensões:

1. Tomada de decisões públicas que são discutidas e pensadas entre pares.

2. A produção, valorização de materiais e instrumentos de ensino e a avaliação da aprendizagem.

3. O relato sistemático das práticas pedagógicas vividas, tomada de decisões coletivas e ações para dar soluções aos desafios da prática docente.

As dimensões anteriores sempre devem ser conjugadas a partir da construção da singularidade e da responsabilidade do processo e do resultado do construto. Dessa forma, os autores propõem com base em Nóvoa $(2001$; 1995) três princípios para a formação de professores de línguas:

1. Considerar o espaço de atuação do professor como central nesse processo.

2. Promover a reflexão coletiva entre pares (professores em formação).

3. Registrar sistematicamente as experiências pedagógicas e divulgá-las.

Garcez e Schlatter (2017) apoiam a ideia de criar espaços para a promoção de diálogos sistemáticos e contínuos para a construção coletiva de soluções para problemas decorrentes das práticas. Além disso, é imprescindível que os professores possam registrar e documentar suas decisões e ações. Para Garcez e Schlatter (2017), assumir a responsabilidade de registrar esse repertório prático é adotar, além da identidade de professor-autor, a identidade de professor-autor-formador. Dessa forma, o professor-autor de suas experiências passa a ser visto como professor-autor-formador que encaminha a prática de outros professores ao divulgar seus relatos, criando assim um circuito de formação. 
A formação sob essa perspectiva é entendida como prática crítica reflexiva que analisa a situação de ensino em determinado contexto. Dessa forma, entendemos a formação como uma relação dialética entre a prática pedagógica, a reflexão e o diálogo entre pares. Nesse marco teórico discutimos algumas perspectivas sobre a formação de professores de PLA. A seguir, apresentamos algumas pesquisas que parte desse paradigma prático sobre a formação de professores de PLA.

\section{Estado da arte}

As pesquisas de Coitinho (2007), Dutra (2010) e Fonseca (2015) analisam, desde uma perspectiva reflexiva, qual é o papel das práticas dos professores de PLA no processo de formação docente. Esses estudos argumentam que é fundamental que a formação inicial de professores parta de uma perspectiva reflexiva para o desenvolvimento e a promoção da autonomia docente.

Também, encontramos o trabalho de Izaki (2013) que analisa as concepções dos professores em formação e a interação com seus estudantes em suas práticas pedagógicas de PLA. O estudo conclui que o enfoque assumido pelos professores, de maneira consciente ou não, determina o tipo de interação construída na aula.

Costa $(2013,2018)$ e Lemos (2014) pesquisam sobre os processos de formação de professores em espaços coletivos. Costa (2013) define "eventos de formação" como os momentos e espaços propícios para aprender a ensinar. Lemos (2014) amplia a discussão sobre os eventos de formação de Costa (2013) em sua pesquisa sobre formação de professores em docência compartilhada. Lemos (2014) conclui que os eventos de formação identificados por Costa (2013) permitem compreender de maneira local e situada o processo de formação de professores.

Mais recentemente, Costa (2018) reconhece a dimensão dos conceitos de professor-autor e professor-autor-formador propostos por Garcez e
Schlatter (2017) ao afirmar que os eventos de formação são iniciativas autorais, locais, colaborativas e resultante de encontros dialogados entre professores no exercício de suas práticas. Assim, identificamos nas pesquisas sobre formação de professores de PLA um paradigma que reconhece as práticas pedagógicas como parte do processo de formação docente. Na próxima sessão, apresentamos a metodologia de pesquisa empregada neste estudo.

\section{Método}

A partir do paradigma da pesquisa qualitativa (Creswell, 2007), optamos pelo uso da metodologia da teoria fundamentada (Glaser e Strauss, 1967; Charmaz, 2009; Birks e Mills, 2015; Urquhart, 2013) que tem como epicentro o contexto e sua interpretação por meio da comparação, reflexão e formulação de hipóteses sobre o que emerge dos dados. Essa metodologia é ideal em pesquisas que têm como objetivo compreender os sentidos de determinadas experiências.

Embora a teoria fundamentada não seja uma metodologia linear, possui certas práticas processuais: coleta de dados, processos de codificação (inicial, focalizada e teórica), escrita de memorandos transversal a toda a pesquisa, refinamento das categorias (amostragem, saturação e classificação teórica) e construção da interpretação narrativa (Creswell, 2008).

Para Charmaz (2009), uma coleta de dados relevantes é essencial para a construção de uma análise coerente e significativa em teoria fundamentada. Para a autora, a entrevista aberta é ideal porque permite que os pesquisadores explorem, analisem e compreendam todas as dimensões sobre as experiências dos entrevistados. Por essa razão, decidimos realizar entrevistas abertas com um enfoque narrativo (Clandinin e Connelly, 2015) que segundo Sandín Esteban (2003), gera conhecimentos sobre os fatos que servem como lentes interpretativas de determinadas vivências. $\mathrm{O}$ uso das entrevistas abertas com enfoque narrativo tem como propósito fundamental proporcionar a esse 
grupo de professores a oportunidade de relatar, assim como de refletir sobre suas trajetórias e experiências como professores de PLA na Colômbia.

\section{Participantes}

Para a realização desse trabalho entrevistamos, por aproximadamente uma hora, vinte e cinco professores de PLA em seis cidades colombianas: Bogotá(10), Cali(6), Cartagena(1), Ibagué(1), Medellín(6) e Pereira(1). A escolha dessas cidades ocorreu por conta da demanda significativa por aulas de PLA nesses contextos. Além disso, Bogotá e Medellín são cidades que realizam o exame Celpe-Bras e seus números de candidatos são expressivos. Essa diversidade territorial tem como objetivo estabelecer uma compreensão ampla sobre as trajetórias profissionais desse grupo de professores de PLA no contexto colombiano.

Especificamente sobre os participantes, entrevistamos quinze homens e dez mulheres. A maioria dos professores (11) é jovem e tem entre 25 a 30 anos, a minoria (5) tem entre 31 a 35 anos e os demais (9) têm mais de 35 anos. Todos têm graduação em áreas diferentes a letras, tais como: fisioterapia, relações internacionais, música, ciências sociais, pedagogia, engenharia, filosofia, história, geologia, administração, medicina veterinária, artes cênicas, publicidade, turismo, jornalismo e psicologia. Também, é importante mencionar que os entrevistados ensinam PLA a mais de 5 anos em diferentes contextos de ensino na Colômbia (escolas, universidades e institutos).

No decorrer das entrevistas consideramos e aplicamos os critérios éticos que correspondem a este tipo de estudo. Todos os professores que voluntariamente concordaram em participar receberam um documento com a descrição dos objetivos desta pesquisa e um termo de consentimento livre e esclarecido antes da entrevista. Além disso, os participantes reconheceram verbalmente o entendimento dos protocolos éticos considerados nesse trabalho: confidencialidade, participação voluntária e a possibilidade de interromper a entrevista e abandonar a investigação a qualquer momento.

\section{Resultados}

Como resultado da análise, do processo de codificação e da categorização das entrevistas construímos a categoria: "debute profissional e formativo" que está composta por quatro subcategorias: 1) contato e identificação com a docência; 2) contextos de trabalho; 3) identidade profissional e formação; e 4) necessidades de formação. A seguir, apresentamos cada uma dessas dimensões interpretativas das trajetórias desse grupo de professores de PLA na Colômbia.

\section{Contato e identificação com a docência}

A maioria dos professores entrevistados são brasileiros que migraram para a Colômbia sem intenção inicial de trabalhar como professores de PLA. O contato com a possibilidade da docência foi resultado das contingências:

\footnotetext{
Eu vim aqui com o objetivo de trabalhar na minha área, minha formação é em história, mas foi muito complicado, porque aqui o currículo é diferente, é outro esquema. Fiquei um pouco desanimada, mas descobri o Instituto de língua portuguesa e pensei: por que não? (professora 19)
}

$\mathrm{Na}$ maioria das vezes, os entrevistados mencionam que essa descoberta profissional se dá pelo contato com outros brasileiros professores de PLA no país:

Várias colegas minhas já estavam dando aula de português e pensei nessa possibilidade por conta delas. (professora 1)

O encontro com compatriotas está relacionado com a condição migratória que caracteriza esse grupo docente e que considera os vínculos com o Brasil altamente significativos:

Desde o ponto de vista dos vínculos, das raízes, eu não poderia querer coisa melhor porque eu moro no Brasil aqui dentro, esse pedacinho é o Brasil e isso me ajuda a lidar com a saudade. (professor 22)

Essa reminiscência de Brasil que o professor se refere é o instituto de língua portuguesa onde trabalha. Esse espaço de reencontro com a língua e a cultura brasileira na Colômbia torna a possibilidade da 
docência atrativa para esse grupo conforme menciona essa professora:

Estar com pessoas de sua nacionalidade obviamente que ajuda a suprir a falta que sentimos do Brasil, porque fazia tempo que eu já estava aqui, e isso era totalmente diferente no meu outro trabalho. (professora 4)

A construção de vínculos sociais e afetivos na Colômbia é importante para esse grupo migrante, mas o encontro com compatriotas brasileiros tende a ser ainda mais significativo por razões de identidade linguística e sociocultural, como afirma essa entrevistada:

Me senti um pouco mais cômoda justamente por estar falando com pessoas da minha mesma língua. Porque existem certas expressões, formas de se comunicar, que você se comunica com pessoas da sua língua e que você não usa com pessoas que não são da sua língua. Então, acaba criando também um déficit de sentimento como se você não se sentisse conectada. (professora 17)

Dessa forma, identificamos que a língua portuguesa passa a ser reconhecida como parte fundamental da identidade brasileira desse grupo de professores:

Minha vida é o Brasil! Dou aulas de português o dia todo, falo mais português que espanhol durante o dia porque falo com os professores em português, minha mãe em casa fala português, eu falo português com meu filho. Acho que, se eu não desse aulas ou se não estivesse no Instituto, deixaria de ser brasileiro. (professor 12)

Percebemos que a língua portuguesa é o elo mais imediato dos professores com sua identidade brasileira. Devido à condição de migração, esse grupo sente que esse vínculo pode se perder com o tempo. Por isso, buscam construir relações com a língua e cultura brasileiras em seu dia a dia na Colômbia:

Minha esposa é colombiana, mas falamos em português aqui, falo com meus gatos em português. Com o tempo, se não estamos praticando, acabamos misturando e o que eu não quero, é isso. (professor 16)

Dessa forma, a relação dos professores com a língua portuguesa é essencial para a construção e preservação de sua identidade brasileira na Colômbia.
Nesse aspecto, a aula de PLA é o espaço ideal para manter essa conexão com o Brasil:

Me vincula ao Brasil e talvez seja uma forma que tenho
de estar no Brasil todos os dias, porque se não fosse
essa possibilidade, eu não gostaria de estar aqui. Eu
gosto da cidade, mas eu gosto muito mais do que faço.
(professora 23)

As aulas de PLA dão para esse grupo de professores a possibilidade de (re)visitar o Brasil por meio do ensino de sua língua e cultura. Reconhecemos, então, que o contato e a identificação desse grupo com a docência de PLA se dá por meio da contingência de sua situação de migração na Colômbia e da intenção de reafirmar sua identidade brasileira.

\section{Contextos de trabalho}

Se por um lado os professores se identificam com o ensino de PLA como forma de se manterem vinculados ao Brasil, por outro lado a Colômbia concede essa possibilidade profissional ao validar a figura do falante nativo. Dessa forma, esse grupo ocupa um lugar legitimado socialmente como estrangeiros que ensinam sua própria língua e cultura. Segundo esta professora, a condição de estrangeiros destina esse grupo à profissão docente como se esse fosse um lugar natural:

Eu acho que, no caso das aulas de português, eles [os estudantes] preferem nativos, como eles nos chamam, porque não só falamos o idioma desde que nascemos, mas porque também vivemos e habitamos o país e podemos trazer a cultura para a aula. As experiências vividas no Brasil acho que são bem valorizadas. (professora 1)

Outro entrevistado complementa essa ideia ao contar como o fato de ser brasileiro o ajudou a encontrar trabalho na Colômbia:

Eu acho, sem dúvida nenhuma, que nos ajudou em muitos aspectos o fato de sermos estrangeiros. Há muitas vantagens em ser brasileiro na Colômbia. O que é muito diferente de ser brasileiro na Alemanha. Então, chegamos a um país que precisa de educadores, formadores, um país que precisa de gente que trabalhe no campo das línguas e que precisa cada vez mais de professores de português. Sem dúvida é uma vantagem ser brasileiro na Colômbia. Isso é o que nos levou, a 
muitos de nós, a ser professores de português. Em outras palavras, se eu estivesse no Brasil, o mais provável é que não fosse professor de português. (professor 3)

Uma professora explica que a valorização do falante nativo faz parte da cultura do país:

O colombiano tem muito a ideia de que tudo que vem de fora é melhor e sabemos que nem sempre é assim. (professora 1)

Nesse contexto em que o falante nativo é altamente valorizado, nos parece apropriado conhecer o ponto de vista de um professor colombiano que comenta:

Me sinto com um pouco de vergonha sobre o que as pessoas vão falar de mim. Quando tem um brasileiro perto eu não gosto de dizer que eu sou professor de português, porque sinto que eu preciso aprender muito mais, e que estou me metendo em algo que não deveria. (professor 10)

Percebemos como a figura do falante nativo é validada no ensino de línguas como uma visão que circula socialmente. No entanto, essa legitimidade concedida aos falantes nativos não é sentida como natural pelos próprios professores brasileiros:

Eu não sinto as aulas de português como um lugar natural que tenho que defender com unhas e dentes. O mundo é dinâmico e o lugar que ocupamos nele também é. (professor 11)

Apesar da valorização simbólica do professor falante nativo, as condições de trabalho na Colômbia, segundo os entrevistados, não são as ideais. Geralmente, os professores têm um contrato de prestação de serviços que paga o valor correspondente ao número de horas lecionadas no mês. Esse tipo de contrato estimula os professores a assumirem o maior número de horas de aula possível:

O salário não é alto e quanto mais você trabalha mais você ganha. Então, como trabalhamos por horas, não por mês, se você trabalha ganha, se você trabalha muito, muitas horas, você ganha mais. (professor 16)

Nesse contexto, as condições de trabalho construídas entre as instituições e os professores limita o potencial papel do professor, conforme afirma este entrevistado:

\section{Acho que o que marcou meu desenvolvimento como professor naquela experiência foi o próprio instituto. Não é apenas o estilo do instituto, é o estilo de qualquer instituto que opera em torno desse tipo de atividade. Você vai ensinar e volta, acabou. Ou seja, não há mais nada, ou seja, seu relacionamento é um relacionamen- to de dar aula, ponto. (professor 3)}

Identificamos que os entrevistados sentem falta de um espaço fora do contexto das aulas para a promoção do desenvolvimento profissional como professores. Podemos fazer um paralelo com o afirmado por Garcez e Schlatter (2017) sobre a importância do intercâmbio das experiências dos professores em seus processos de formação. Desse modo, reconhecemos que as instituições educativas podem propiciar a formação de seus professores:

Vai depender muito do lugar onde você está trabalhando e das condições de diálogo, de crescimento profissional e pessoal, nem todo o lugar favorece isso. (professor 11)

Então, compreendemos que os professores falantes nativos são legitimados e valorizados no exercício de sua prática de ensino de PLA na Colômbia. Apesar disso, os professores entrevistados não enxergam esse lugar como natural e consideram que o tipo de vínculo trabalhista ao qual estão submetidos não potencializa seu desenvolvimento profissional.

\section{Identidade profissional e formação}

Ainda que o contexto colombiano possibilite o exercício da docência de PLA dos professores falantes nativos, esse grupo manifesta algumas crises de identidade profissional:

É como se eu estivesse roubando o emprego de outra pessoa mais qualificada porque as pessoas estudam Letras para ser professor. E eu não estudei nada e sou professora? Como assim? Eu também estou ocupando uma vaga. Se alguém fosse engenheiro sem ter feito tudo que eu fiz, eu ficaria pensando que essa pessoa não fez nada e está trabalhando como engenheira, que absurdo. (professora 21) 
Essa falta de uma formação específica na área de Letras faz com que esses professores se sintam em território alheio:

Sinceramente, eu não sou uma boa professora. Não pode ser. Tem pessoas aqui que fizeram Letras, é a formação deles. Eu não tenho essa formação. Então, tentei descobrir por curiosidade as minhas fortalezas. Aí descobri conversando e perguntando para me encontrar nesse mundo que não é meu. Eu deveria ter estudado isso, e respeito quem estudou. (professora 14)

Os professores afirmam que se sentem limitados no exercício de suas aulas de PLA por conta da falta da formação específica na área de Letras:

Eu tenho muitas limitações nessa vida profissional de professor, então, sem dúvida nenhuma que é uma limitante, sempre me perguntei sobre a questão da ausência da formação em Letras. Sempre me perguntei: mas isso aqui é para outro tipo de profissional? A ausência desse tipo de conhecimento ou desse tipo de estudo obviamente me limita. (professor 3)

Essa conjuntura evidencia a importância e a aspiração de formação dos professores:

Eu ainda quero estudar Letras, algum dia quero, por curiosidade, por conhecimento, talvez eu me decepcione e vou me dar conta de que aprendo mais estudando sozinha em casa ou dando aula, planejando as aulas mais que em uma universidade, mas eu tenho vontade. (professora 23)

Assim, entendemos que os entrevistados sentem crises de identidade profissional pela falta de formação em Letras. Por não contar com essa formação específica, os professores se sentem limitados no encaminhamento de suas práticas pedagógicas cotidianas (planejamento, materiais, métodos e avaliação) conforme propõe Almeida Filho (1993).

\section{Necessidades de formação}

Reconhecemos que a falta de uma formação específica sentida pelo grupo de professores suscita inseguranças em suas práticas que são de duas naturezas: uma pedagógica (como ensinar?) e outra disciplinar (o que ensinar?). Sobre a primeira, identificamos que os professores se sentem inseguros por não saber como ensinar a língua portuguesa:
Uma vez uma médica me disse que queria aprender português e me perguntou se eu poderia dar aulas. Eu respondi que sabia português; mas, que não era professora, ou seja, que eu não sabia como ensinar, foi estranho porque parecia que eu não sabia português porque eu não sabia ensinar. (professora 13)

Assim, os professores reconhecem a necessidade de um saber pedagógico que oriente e situe o ensino de pla. Nesse sentido, reconhecemos a necessidade de refletir sobre o exercício pedagógico a partir de diálogos entre teoria e prática no processo de formação de professores (Garcez e Schlatter, 2017; Gimenez, 2005).

Com respeito ao aspecto disciplinar, os professores afirmam que se sentem inseguros com as perguntas dos estudantes sobre aspectos da língua portuguesa:

Então, meu medo não era o medo da sala de aula, ficar de pé, falar em público, este não era meu medo, meu medo era não saber responder coisas que eu não sabia, que não era meu território. (professora 4)

Esse é um sentimento recorrente por parte desse grupo porque os estudantes fazem perguntas sobre aspectos da língua que são naturalizados pelos falantes nativos. Por essa razão, é importante que os professores reflitam sobre a língua em uso no seu processo de formação. Dessa forma, o professor pode pensar em sua própria língua desde a perspectiva do outro que a aprende. Além disso, compreendemos que o conhecimento disciplinar está subordinado ao conhecimento pedagógico:

\footnotetext{
Quando os estudantes me perguntam alguma coisa gramatical que eu acho complicada, eu digo que vou pesquisar para trazer uma resposta na próxima aula. Então, na próxima aula eu explico outra vez de uma nova forma para que o estudante possa entender. Assim, busco uma forma na qual os estudantes realmente possam entender o tema. Porque às vezes não é fácil, a gente se pergunta: como eu explico isso? (professora 13)
}

Nessa circunstância, consideramos relevante a proposta de construção e divulgação dos relatos de práticas de PLA (Garcez e Schlatter, 2017) como parte das necessidades de formação dos professores na Colômbia: 
Acho que talvez a falta de preparação, estudo da língua portuguesa anterior, é o principal motivo de insegurança. Ou talvez, por exemplo, já aconteceu várias vezes que um estudante me pergunta por que algo é de alguma maneira e eu não sei responder, então vem a insegurança. (professor 7)

Embora a insegurança seja constante na trajetória profissional desse grupo, essa sensação aumenta substancialmente no desenvolvimento de cursos novos:

Os desafios se apresentam quando a gente muda de nível, sobretudo aqui, por exemplo, eu estou muito habituado a ensinar o nível 3. Se devo dar o nível 7 que é um nível que, por exemplo, eu nunca dei, teria que considerar um novo desafio, ter que aprender os conteúdos. Saber, eu sei, mas construir uma experiência acadêmica de algo que a gente não está acostumado, sim implica um pouco mais de cuidado, mais atenção. Quando me tiram de minha zona de conforto, é que encontramos o mais valioso da aprendizagem. E isso sempre é desafiador para um professor. (professor 5)

Podemos associar essa sensação de insegurança em cada novo curso praticado pelos professores com o proposto por Gimenez (2005) sobre a necessidade de romper com a separação entre formação inicial e contínua de professores. Para a autora é importante criar espaços para discussão e análise crítica da prática docente independente se esse espaço ocorra no contexto de uma formação inicial ou contínua. Também, identificamos a necessidade de uma formação de professores que promova a construção de práticas autônomas para o ensino de PLA nesse contexto, conforme propõe Almeida Filho (1993).

Apesar das inseguranças pedagógicas e disciplinares, esse grupo escolhe a docência como profissão desde suas primeiras experiências:

No primeiro dia de aula eu sabia que queria fazer isso toda a vida, porque por mais caótico que tenha sido, eu gostei muito. Cheguei em casa muito feliz, foi muito prazeroso, senti que tinha superado esse medo de falar com outras pessoas. Assim, foi realmente bonito. (professor 18)

É interessante notar que essa escolha profissional extrapola o contexto colombiano:

Para qualquer lugar do mundo que eu for, tenho planos com a minha esposa de ir para outros países, se eu tiver a oportunidade de ensinar português, é português que eu vou ensinar. (professor 7)

Então, compreendemos que os professores sentem necessidades de formação em dois aspectos interrelacionados: pedagógicos e linguísticos. A naturalização do português pelos falantes nativos faz com que os professores se sintam seguros quanto ao uso da língua, mas os torna inseguros com relação ao seu ensino ou interpretação.

Em resumo, os resultados dessa pesquisa apontam que as trajetórias de vida dos professores estabelecem contatos com a docência que a priori não era sua intenção. A situação de migração destina esse grupo a um lugar natural no mercado de trabalho colombiano como professor falante nativo. Apesar desses professores não considerarem o ensino de PLA no país como seu lugar natural devido a um déficit de formação, esse grupo se identifica com a profissão docente e decide segui-la pelo fato de poderem exercer sua identidade nacional de maneira cotidiana em suas práticas de ensino.

\section{Discussão}

Os professores entrevistados aludem frequentemente a sua condição de migração na Colômbia e como sua identidade brasileira se relaciona com a docência de PLA no país que os acolhem. Contudo, os temas de suas aulas (língua e cultura brasileira) estão subjugados a outros tipos de conhecimentos: linguístico e pedagógico. Embora os professores se sintam identificados com o ambiente de ensino de PLA pelo fato de serem nativos, consideram que esse não é um lugar natural. Ao contrário, percebemos que esse grupo não se identifica totalmente com a profissão docente devido à falta de uma formação em Letras.

Nesse sentido, como propõem Grannier (2001) e Almeida Filho (1993) espera-se que o professor de PLA além de ter conhecimentos sobre língua e cultura brasileira seja um profissional capaz de reconhecer os processos de aquisição e as metodologias/ abordagens de ensino de línguas adicionais. E apesar de que o contexto colombiano não priorize a 
oferta desse tipo de formação profissional para professores de PLA, a identificamos como crucial.

Além disso, é possível perceber que esse reconhecimento do professor falante nativo gera crises de identidade profissional nesse grupo de docentes. Por não considerarem esse lugar como natural os professores entrevistados sentem suas identidades dispersas em um campo onde potencialmente passam a ser: um profissional de uma área diferente a Letras que dá aulas de português, um estrangeiro brasileiro que ensina sua língua e cultura e/ou um professor de pla na Colômbia. Conforme aponta Gimenez (2005) um desafio para a formação dos professores de línguas adicionais é a construção e compreensão da identidade profissional dos formadores de professores que se encontra difusa entre pesquisador/formador.

Para a autora, a posição de pesquisador tem mais prestígio que a de formador porque essa última está associada com a prática pedagógica. Então, para Gimenez (2005), é necessário que formadores de professores se vejam como tal. Neste caso, consideramos que a qualificação professor falante nativo também impede a construção e a compreensão da identidade profissional desses professores.

Almeida Filho (1993) argumenta que por meio da reflexão das dimensões de suas próprias práticas, os professores se reconhecem como profissionais docentes. Garcez e Schlatter (2017) afirmam que a figura do professor-autor-formador permite a (re)construção da identidade profissional do professor por meio da pesquisa e reflexão sobre suas práticas pedagógicas. Portanto, é indispensável pensar nesses aspectos para a implementação de programas de formação de professores de PLA no contexto colombiano.

\section{Conclusões}

Em primeiro lugar, os resultados dessa pesquisa contribuíram para o entendimento das trajetórias profissionais dos professores de PLA na Colômbia. Entendemos que é fundamental compreender as circunstâncias da área para entender e reconhecer os processos de identificação e formação profissional, de grande parte de seu corpo docente.

Em segundo lugar, identificamos que o lugar natural como professores de PLA concedido aos brasileiros no contexto colombiano é uma construção social que não deve impedir que se construam propostas de formação docente que estimulem o intercâmbio de experiências para a promoção de melhores práticas pedagógicas.

Em terceiro lugar, constatamos a necessidade da criação de cursos de graduação e/ou licenciatura orientados para a formação dos professores de PLA na Colômbia. Com essas iniciativas, podemos transformar esse panorama profissional que privilegia falantes nativos e apostar em cursos de formação que possam criar redes de profissionais que além de discutir teoricamente suas práticas, possam desenvolver pesquisas que ajudem no processo de ensino e aprendizagem de PLA nesse contexto específico assim como, fortalecer essa área de conhecimento no país.

Embora tenhamos encontrado dados relevantes sobre o "debute profissional e formativo" desse grupo de professores de PLA na Colômbia, é importante (re)conhecer também, como esses profissionais conseguiram se apropriar da docência. Em outras palavras, é crucial que futuras pesquisas expliquem quais são e como interagem entre si os elementos que ajudaram a que esse grupo se construísse como professores de PLA no país. Uma maior compreensão sobre como esse grupo aprendeu a ensinar PLA nesse contexto também pode orientar o planejamento e implementação de futuros programas de formação para esses profissionais da educação na Colômbia.

\section{Referências}

Almeida Filho, J. C. P. de. (1993). Dimensões comunicativas no ensino de línguas. Pontes Editores.

Andrade-Stanzani, L. (2019). Diálogos interculturais na formação de professores de português na fronteira colombo-brasileira: uma necessidade. In Interculturalidady formación deprofessores:perspectivas pedagógicas y multilinguës. (pp. 77-207). Ediciones Uniandes. https://doi.org/10.30778/2019.62 
Birks, M., \& Mills, J. (2015). Grounded theory: A practical guide. Sage.

Cárdenas, M. L. (2010). Encuentros y desencuentros em la formación de profesores de inglés en Colombia: una mirada a las políticas del "Programa Nacional de Bilingüismo”. Em T. Gimenez, \& M. C. G. Monteiro (Orgs.), Formação de professores de línguas na América Latina e transformação social (pp. 19-44). Pontes Editores.

Charmaz, K. (2009). A construção da teoria fundamentada: Guia prático para análise qualitativa. Artmed.

Clandinin, D. J., \& Connelly, F. M. (2015). Pesquisa narrativa: Experiência e história em pesquisa qualitativa. Editora da Universidade Federal de Uberlândia. https://doi.org/10.14393/ EDUFU-978-85-7078-279-3

Coitinho, V. P. (2007). A prática docente do professor de português para estrangeiros para uma aprendizagem crítica: Formação de professores de português para estrangeiros. Pontifícia Universidade Católica de Curitiba. http://www.biblioteca.pucpr.br/tede/ tde_busca/arquivo.php?codArquivo $=895$

Costa, E. V. da. (2013). Práticas de formação de professores deportuguês lingua adicional em um instituto cultural brasileiro no exterior. Universidade Federal do Rio Grande do Sul.

Costa, E. V. da. (2018). Eventos de formação de professores de português como língua adicional: A organização das práticas e as trajetórias de participação em um estudo interpretativo sobre aprender a ensinar. Universidade do Rio Grande do Sul.

Creswell, J. W. (2007). Qualitative inquiry and research design: Choosing among five approaches. Sage Publications.

Creswell, J. W. (2008). Educational research: Planning, conducting, and evaluating quantitative and qualitative research. Prentice Hall.

Dutra, A. F. (2010). O processo reflexivo-colaborativo na formação inicial de professores de português lingua estrangeira. Universidade Federal de Minas Gerais. https://repositorio.ufmg.br/bitstream/1843/ LETR-8TEMPG/1/tese.pdf

Elliot, L., Judd, E. L., Tan, L., \& Walberg, H. J. (2001). Teaching additional languages. Genebra: International Academy of Education/International Bureau of Education. https://www.researchgate.net/ publication/44826006_Teaching_additional_languages

Elliott, J. (1991). El cambio educativo desde la investigaciónacción. Ediciones Morata.
Fonseca, D. F. da. (2015). A prática reflexiva do professor de português - lingua estrangeira. Universidade Estadual de Campinas. http://repositorio.unicamp. br/bitstream/REPOSIP/269575/1/Fonseca_ DayseFarias_M.pdf

Garcez, P., \& Schlatter, M. (2017). Professores-autoresformadores: Princípios e experiências para a formação de profissionais de educação linguística. In Diálogos (im)pertinentes entre formação de professores e aprendizagem de linguas (pp. 13-36). VI CLAFPL. https://doi.org/10.5151/9788580392708-01

Gimenez, T. (2005). Desafios contemporâneos na formação de professores de línguas: Contribuições da Linguística Aplicada. In M. M. Freire, M. H. V. Abrahão, \& A. M. F. Barcelos (Eds.), Linguistica aplicada e contemporaneidade (pp. 183-201). Pontes Editores e ALAB.

Glaser, B. G., \& Strauss, A. L. (1967). The discovery of grounded theory. Routledge.

Grannier, D. M. (2001). Perspectivas na formação do professor de português como segunda língua. Cadernos Do Centro de Linguas, USP, 4.

Izaki, M. A. (2013). Professores em formação: significados construidos no processo de interação em sala de aula de português lingua estrangeira. Universidade Federal de São Carlos. https://repositorio. ufscar.br/bitstream/handle/ufscar/5776/5468. pdf ? sequence $=1$ \&isAllowed $=y$

Lemos, F. C. de. (2014). A formação do professor para o ensino de lingua adicional em ambientes digitais com docência compartilhada. Universidade Federal do Rio Grande do Sul.

Nóvoa, A. (1995). Formação de professores e profissão docente. In: Os professores e a sua formação. (pp. 13-33). Dom Quixote.

Nóvoa, A. (2001). Antonio Nóvoa: "professor se forma na escola”. Entrevista com Antonio Nóvoa concedida a PaolaGentili.RevistaNovaEscola. http://novaescola. org.br/conteudo/179/entrevista-formacaoantonio-novoa?utm_source $=$ gestao+escolar\&utm m e d i u $m=f a c$ e b o o k \& u t m campaign $=$ mat $\% \mathrm{C} 3 \% \mathrm{~A} 9$ ria\&utm_content $=$ link

Patiño, C. A. G. (2005). El portugués como lengua extranjera en Bogotá: Situación actual y perspectivas para su posible inclusión en el curriculo de la educación básica y media. Universidad Nacional de Colombia, Bogotá. http://www.humanas. unal.edu.co/red/files/4913/5488/2246/ Patino_Garzon_Camilo_Andres._El_portugues_ como_lengua_extranjera_en_Bogota.pdf 
Sandín Esteban, M. P. (2003). Investigación cualitativa en educación. Fundamentos y tradiciones. Fundamentos y Tradiciones. Mc Graw and Hill Interamericana.

Scaramucci, M. V. R. (2012). O exame Celpe-Bras e a proficiência do professor de Português para falantes de outras línguas. Revista Digilenguas, 12(Junio), 48-67.

Schlatter, M., \& Garcez, P. (2009). Linguas adicionais (espanhol e inglês). Referências curriculares do Estado do Rio Grande do Sul: Linguagem, códigos e suas tecnologias (vol. 1). http://servicos.educacao.rs.gov. br/dados/refer_curric_voll.pdf

Schön, D. A. (1991). The reflective practitioner: How professionals think in action. Ashgate.

Stenhouse, L. (1996). La investigación como base de la enseñanza. Ediciones Morata.

Urquhart, C. (2013). Grounded theory for qualitative research: A practical guide. Sage. https://doi. org/10.4135/9781526402196

Como citar este artigo: Andrade-Stanzani, L. (2021). Identidade profissional e formação de professores de português como língua adicional na Colômbia. Íkala, Revista de Lenguaje y Cultura, 26(2), 303-316. https://doi.org/10.17533/udea.ikala.v26n2a02 